\title{
Instructional leadership practices of rural school principals.
}

\begin{abstract}
This paper discusses findings from a qualitative study employing in depth interviews with three secondary rural school principals in relation to their instructional leadership practices. The schools involved represent three levels of performance; excellent, average and poor. Information in the form of observations and document analysis were also gained. The findings of the study showed that there are three main instructional leadership practices amongst the principals studied: improving teaching and learning programs, enhancing school climate and networking.
\end{abstract}

Keyword: Rural school principals; Instructional leadership practices. 